\title{
Analysis of the publishing rate and the number of citations of general surgery dissertations
}

\author{
Burhan Mayir, Tuna Bilecik, Tuğrul Çakır, Uğur Doğan, Umut Rıza Gündüz, Arif Aslaner, Mehmet Tahir Oruç
}

\begin{tabular}{|c|c|}
\hline \multirow[t]{5}{*}{ ABSTRACT } & $\begin{array}{l}\text { Objective: A dissertation is a scientific document. However, if it is not published in a scientific journal, it will gain ac- } \\
\text { cess to only a limited audience and thus will be unable to achieve its objective. Nevertheless, the rate of publishing } \\
\text { in journals is not high among dissertations. In this study, we aimed to investigate the publishing rates of general } \\
\text { surgery dissertations in journals and the total number of citations. }\end{array}$ \\
\hline & $\begin{array}{l}\text { Material and Methods: All medical dissertations that have been prepared at general surgery departments of uni- } \\
\text { versity hospitals and presented between the years } 2006 \text { and } 2008 \text { were analyzed. The authors checked whether } \\
\text { the dissertations were published in a journal or not, by searching the dissertation in } 4 \text { different resources with the } \\
\text { name of their authors. }\end{array}$ \\
\hline & $\begin{array}{l}\text { Results: Two hundred and thirty-two dissertations were included. Half of those dissertations were experimental animal } \\
\text { studies. Seventy dissertations were published in various journals. Fifty one }(22 \%) \text { of these were published in Science } \\
\text { Citation Index Expanded journals, while } 19(8.1 \%) \text { of them were published in Turkish non-Science Citation Index Ex- } \\
\text { panded journals. There was no significant difference in terms of publishing rates between study types. The number of } \\
\text { annual citations per article was 1.1. The writer of the dissertation was the first author in } 35(68,6 \%) \text { articles. }\end{array}$ \\
\hline & $\begin{array}{l}\text { Conclusion: The publishing rates of dissertations in general surgery is low, with only } 22 \% \text { being published in Science Ci- } \\
\text { tation Index Expanded journals. The citation rate was also detected to be low in our study. Consequently, a dissertation } \\
\text { should be considered as a scientific research study and planned as such, not as obligatory assignments. The publishing } \\
\text { rates of dissertations should be increased, and authors should be led and encouraged to publish their dissertations. }\end{array}$ \\
\hline & Keywords: Dissertation, education, publication, research \\
\hline
\end{tabular}

Cite this paper as: Mayir B, Bilecik T, Çakır T, Doğan U, Gündüz UR, Aslaner A, et al. Analysis of the publishing rate and the number of citations of general surgery dissertations. Turk J Surg 2017;33(1):33-36.

Clinic of General Surgery, Antalya Training and Research Hospital, Antalya, Turkey

Address for Correspondence
Burhan Mayir
e-mail: burmay@yaho0.com
Received: 04.05 .2015
Accepted: 10.07 .2015
Available Online Date: 27.10 .2016
OCopyright 2017
by Turkish Surgical Association
Available online at
www.turkjsurg.com

\section{INTRODUCTION}

A dissertation is a scientific document reflecting qualifications of a medical doctor who is to become specialized in making specific research studies and analyses in his discipline and drawing scientific conclusions from analyses. The Regulation on Medical Specialization in Turkey requires that all candidates prepare and submit medical dissertations at the completion of their medical residency. However, the rate of dissertations published in a scientific journal is not high in our country $(1,2)$. In this study, we aimed to investigate the publishing rates of general surgery dissertations in journals and the total number of citations.

\section{MATERIAL AND METHODS}

All medical dissertations that have been prepared in general surgery departments of university hospitals and presented between the years 2006 and 2008 were analyzed within the scope of the study. Dissertations were identified by searching the Electronic Archive of Higher Education Council Dissertation Center (http://tez.yok.gov.tr/UlusalTezMerkezi/) database. Data regarding the subject and type of research, as well as the university hospital name were recorded.

Afterwards, the dissertations were sought in different databases, i.e. PubMed, Thomson Reuters Web of Science, Google Scholar database, and Turkmedline website (www.turkmedline.net) through which many international journals can be reached, by the author names to check whether they had been published in a journal or not. In case of publication; if the journal was included in the Science Citation Index Expanded (SCIE), the date when the article was published, the first author, the person who made the article publicly available, and the number of citations to the related article were evaluated from Thomson Reuters Web of Science. Citations were assessed by publication date, and the number of citations per year was determined.

This study was performed in accordance with the ethical standards of the Declaration of Helsinki.

\section{Statistical Analysis}

Study data was analyzed using the Statistical Package for Social Sciences (SPSS Inc.; Chicago, IL, USA) 16.0. Categorical values were analyzed by Chi-square test and non-parametric values were analyzed by 
Mann-Whitney $\mathrm{U}$ test. $\mathrm{p}$ value below $<0.05$ was considered as statistically significant.

\section{RESULTS}

Two hundred and thirty-two dissertations were completed between 2006 and 2008. 116 (50\%) of those dissertations were animal studies while the other $116(50 \%)$ were clinical studies. Of all the clinical studies, 19 (8.2\%) were randomized prospective clinical studies, $10(4.3 \%)$ were non-randomized prospective clinical studies, 22 (9.5\%) were case-control studies, 9 (3.9\%) were cross-sectional studies, and 55 (23.8\%) were case series. Only 70 (30\%) of all those dissertations have been published in journals. 51(22\%) dissertations were published in SCIE journals, while 19 (8.1\%) were published in Turkish nonSCIE journals. There was no significant difference between study types in terms of publishing rate as shown in Table 1.

The time spent for a dissertation to be published after submission ranged from 1 to 7 (2.8) years. This interval was approximately 2.8 years for SCIE journals, and was 2.8 years for Turkish non-SCIE journals. There was no significant difference between journal types regarding the time to publication $(p=0.621)$.

When SCIE journals were considered, the number of citations was between 0 and 15. Thirty-six of 51 articles have been cited in different studies while 15 of them have never been referred to. The number of references per publication was 1.1/year. Only 23 publications were cited more than once in a year.

When the authorship order in the published dissertations was analyzed it was determined that the writer of the dissertation was the first author in 35 dissertations that were published in SCIE journals. The dissertation's advisor was stated as the first author in 8 articles, while an author other than the owner or the advisor was the first author in the other 8 papers. Within the Turkish non-SCIE journals, the first author was the owner of the dissertation in 17 articles. The advisor ranked first in one publication while in another one someone other than the owner and the advisor was credited as the primary author. There was no significant difference between these two groups regarding authorship order $(p=0.284)$. When publishing rates of dissertations in SCIE journals was assessed by subject it was found that most studies were related to colorectal cancer, intra-abdominal adhesions, and ischemia reperfusion injury as shown in Table 2.

We also analyzed dissertation publishing rates by the location of the universities. According to this analysis, 103 (44.4\%) have been conducted at the universities located in the 3 biggest cities of Turkey, namely Istanbul, Ankara and Izmir, while the remaining 129 (55.6\%) have been carried out at universities in other cities of the country. When the publishing rate in SCIE journals was considered, it was observed that $29.1 \%$ of the dissertations completed in the aforementioned 3 big cities have been published in contrast to $16.3 \%$ of dissertations from other cities $(p=0.019)$.

\section{DISCUSSION}

Although the process may change from one country to another, in some countries including Turkey, medical doctors are required to prepare and present a dissertation in completion of their residency training. Dissertation preparation helps a specialist candidate improve his/her skills required for both
Table 1. Publishing rates of dissertations according to study types

\begin{tabular}{|lccc|}
\hline Study type & Total & Published & $\begin{array}{c}\text { Publishing } \\
\text { rate (\%) }\end{array}$ \\
\hline $\begin{array}{l}\text { Randomized prospective } \\
\text { clinical studies }\end{array}$ & 19 & 3 & 15.8 \\
\hline $\begin{array}{l}\text { Non-randomized prospective } \\
\text { clinical studies }\end{array}$ & 10 & 3 & 30.0 \\
\hline Case-control studies & 22 & 5 & 22.7 \\
\hline Cross-sectional studies & 9 & 1 & 11.1 \\
\hline Case series & 56 & 12 & 21.4 \\
\hline Animal studies & 116 & 27 & 23.0 \\
\hline
\end{tabular}

Table 2. Publishing rates of dissertations according to subjects

\begin{tabular}{|lc|}
\hline Dissertation subject & Publishing rate (\%) \\
\hline Colorectal cancer & 41 \\
\hline Intraabdominal adhesion & 35 \\
\hline Ischemia-reperfusion injury & 27 \\
\hline Thyroid diseases & 21 \\
\hline Colorectal anastomosis & 20 \\
\hline Breast diseases & 18 \\
\hline Pancreas diseases & 14 \\
\hline
\end{tabular}

performing and interpreting research. While preparing a dissertation, new questions and hypothesis are set, a literature review is conducted, appropriate methods are determined for the study, and the required data is collected. Afterwards, the collected data is analyzed and the researcher tries to draw a conclusion from this analysis. Results obtained in the scope of the study are discussed in light of previous information, and presented as a study paper. Thus, it provides the specialist candidate the skills to conduct research studies and offers him/her an opportunity to use these skills (3).

A dissertation is considered a scientific paper regardless of whether it is published in a journal or not. A dissertation reveals results and informs readers about the related subject. However, if it is not published in a scientific journal, it will gain access to only a limited audience and thus will be unable to achieve its objective (4). A dissertation should be published as a scientific article to contribute to the national or international scientific literature. The publication of a dissertation is a significant marker indicating the quality of both the dissertation and the institution where the relevant study took place (5). Furthermore, if a dissertation is not published, it may be considered as a waste of time, work, and financial resource. Another ethically unfavorable aspect is that thousands of experimental animals are being used in the research phase of dissertations; therefore, if the dissertation is not published such animals may be considered to have been used for non-scientific purposes.

There is limited information in the literature regarding the publishing rate of general surgery dissertations, but relevant studies have reported a rate ranging between $17 \%$ and $52 \%$ (6-9). When the studies carried out in our country are taken 
into consideration, the publishing rate is not very high. The low publishing rate may be related to the authors' not having academic expectations, the lack of incentives supporting publications, and the requirement of writing the dissertation in foreign languages such as English $(1,10)$. A Turkish study analyzing dissertations submitted between 1980 and 2005 identified that $6.2 \%$ have been published in journals that were included in the Medline database. The same study reported that in 2000 the number of published dissertations increased as compared to previous years. It was also indicated that the publishing rate changed with medical specialty, and that studies from surgical departments had a lower share in publications. According to that study, dissertations on general surgery were published at a rate of $5 \%$ (1). Another study from Turkey analyzed dissertations and doctoral dissertations on public health and reported that $11.9 \%$ were published in international journals while $18 \%$ were published in national medical journals. Similar to the aforementioned study, this study also reported that this rate increased in 2001 (2).

In our study, we found a higher publishing rate for dissertations as compared to previous studies. This may be related to different reasons. First of all, we searched 4 different resources to identify the publishing rate for medical dissertations. Thus, we were able to find dissertations which had been published but were not available on the PubMed website. We think that since previous studies were mainly based on PubMed database, researchers may have failed to notice several dissertations that have been published but not included in the PubMed. It was stated in the previous studies that the publishing rate showed an increase since 2000 , and as our study analyzed dissertations between 2006 and 2008 it may have reflected this tendency. The increase in publishing rate may also be correlated with the fact that the included dissertations were conducted at university hospitals.

Ozgen et al. (1) suggested that the publishing rate of dissertations completed at university hospitals was 5 times higher as compared to the ones carried out at state hospitals. Therefore, this study analyzing only the dissertations completed at university hospitals revealed a higher publishing rate than other series. Other factors which may have increased the publishing rate may include the fact that becoming an academic faculty member is a more preferred profession today in our country as compared to the past. Therefore, one may prefer having published papers, which is a significant contributing factor in the academic field. Sayek et al. (11) reported that while those who wanted to have an academic career had their dissertations published at a rate of $82.4 \%$ in contrast to the $57.1 \%$ rate among those without such academic expectations. The widespread use of internet has facilitated the access to reference articles, and enhanced both the submission of manuscripts to journals and the procedures within the publication phase. Subsequently, internet has paved the way for publishing and encouraged the authors. Additionally, English has become a more commonly used language making it easier to translate dissertations into foreign languages. Thus, it has become easier for authors to prepare manuscripts for international journals. The obligation to publish in foreign languages for international medical journals may have been a cause of the low publishing rate in the past (1). Universities have also improved technically and are focusing more on the importance of research studies, which may have encouraged original studies in medical disciplines.

According to study types, half of the dissertations were animal studies. There may be different reasons for preferring animal studies for dissertation planning. As animal studies are more likely to provide original data, they might have a higher potential for publication. In this study, we also observed that animal studies had a higher publishing rate as compared to clinical studies, nevertheless, the difference was not significant. Animal studies do not require as much effort as clinical studies and they can be completed within relatively shorter time periods. The need to include a significant number of subjects, long follow-up, and possible data loss due to losing the patient during follow-up make clinical studies more difficult than animal studies. Although a prospective randomized study is the most valuable study type for medical disciplines, it is not always preferred as it requires both long time and hard work.

The present study also analyzed authorship. When SCIE journals were taken into consideration, $68 \%$ of the dissertations were published by the main author. This rate was $88 \%$ for Turkish non-SCIE journals. Similar to our study, Sipahi et al. (2) observed that the dissertation writer was the first author in $70 \%$ of international journals. This issue is ethically controversial since the individual who conducts the study should be credited as the first author.

The main limitation of the present study is that we may have overlooked some published dissertations due to different reasons, especially surname changes for female authors, although four different sources were checked to see whether the dissertations were published or not.

In this study, different from other studies on the subject, we have also investigated the citation rate of articles. Although citation of an article is not the only determinant for its quality, it is an important indicator. This is the first study attempting to get an idea on the quality of dissertations by evaluating the number of relevant citations. According to our results, published manuscripts have been cited 1.1 times per year. While 15 articles have never been cited, only 23 articles have been referred to more than once a year. These results generate a negative opinion about the quality of dissertations carried out in our country.

\section{CONCLUSION}

Although the publishing rate of dissertations in our country was higher in our study as compared to previous results, it was determined that $70 \%$ of Turkish-origin dissertations have not been published in either national or international journals. The citation rate was also detected to be low in our results. Consequently, a dissertation should be considered as a scientific research study and should be planned and approached as such. The publishing rates of dissertations should be increased, and authors should be led and encouraged to publish their dissertations.

Ethics Committee Approval: Authors declared that the research was conducted according to the principles of the World Medical Association Declaration of Helsinki "Ethical Principles for Medical Research Involving Human Subjects", (amended in October 2013). 
Peer-review: Externally peer-reviewed.

Author Contributions: Concept - B.M.; Design - B.M.; Supervision B.M., M.T.O.; Resources - B.M., T.B., T.Ç., U.D., A.A., U.R.G.; Materials - B.M., T.B., T.Ç., U.D., A.A., U.R.G.; Data Collection and/or Processing - B.M.; Analysis and/or Interpretation - B.M., M.T.O.; Literature Search - B.M.; Writing Manuscript - B.M.; Critical Review - B.M., T.B., T.Ç., U.D., A.A., U.R.G., M.T.O.

Conflict of Interest: No conflict of interest was declared by the authors.

Financial Disclosure: The authors declared that this study has received no financial support.

\section{REFERENCES}

1. Ozgen U, Egri M, Aktas M, Sandıkkaya A, Ozturk OF, Can S, et al. Publication pattern of Turkish medical theses: Analysis of 22,625 medical theses completed in years 1980-2005. Turkiye Klinikleri J Med Sci 2011; 31: 1122-1131. [CrossRef]

2. Sipahi H, Durusoy R, Ergin I, Hassoy H, Davas A, Karababa A. Publication rates of public health theses in international and national peer-review journals in Turkey. Iran J Public Health 2012; 41: 3135.

3. Ogunyemi D, Bazargan M, Norris K, Jones-Quaidoo S, Wolf $K$, Edelstein $\mathrm{R}$, et al. The development of a mandatory medical the- sis in an urban medical school. Teach Learn Med 2005; 17: 363369. [CrossRef]

4. Dhaliwal U, Kumar R. An observational study of the proceedings of the All India Ophthalmological Conference, 2000 and subsequent publication in indexed journals. Indian J Ophthalmol 2008; 56: 188-194. [CrossRef]

5. Nieminen P, Sipilä K, Takkinen HM, Renko M, Risteli L. Medical theses as part of the scientific training in basic medical and dental education: experiences from Finland. BMC Med Educ 2007; 7: 51. [CrossRef]

6. Dhaliwal U, Singh N, Bhatia A. Masters theses from a university medical college: publication in indexed scientific journals. Indian J Ophthalmol 2010; 58: 101-104. [CrossRef]

7. Salmi LR, Gana S, Mouillet E. Publication pattern of medical theses, France, 1993-98. Med Educ 2001: 35: 18-21. [CrossRef]

8. Frković V, Skender T, Dojćinović B, Bilić-Zulle L. Publishing scientific papers based on Master's and Ph.D. theses from a small scientific community: case study of Croatian medical schools. Croat Med J 2003; 44: 107-111.

9. Caan W, Cole M. How much doctoral research on clinical topics is published? Evid Based Med 2012; 17: 71-74. [CrossRef]

10. Ullrich $\mathrm{N}$, Botelho $\mathrm{CA}$, Hibberd $\mathrm{P}$, Bernstein $\mathrm{HH}$. Research during pediatric residency: predictors and resident-determined influences. Acad Med 2003; 78: 1253-1258. [CrossRef]

11. Sayek I, Yorgancı K. Genel cerrahi uzmanlık eğitiminde tez çalışmaları: Bir üniversite kliniği deneyimi. Ulus Cerrahi Derg 2000; 16: 56-60. 